\title{
Leitura na Educação em Ciências
}

São inúmeros os estudos dedicados ao desenvolvimento da Educação em Ciências enquanto área de pesquisa no Brasil. Neles são apontados antecedentes e possíveis fatores que teriam levado à sua constituição ou ao percurso de alguns aspectos dessa área. Dentre esses trabalhos, citam-se aqui: Almeida (1989, 2012), Almeida Jr. (1979, 1980); Barra e Lorenz (1986); Delizoicov, Slongo e Lorenzetti (2013); Ferreira, Gomes e Lopes (2001); Ferreira e Moreira (2001); Krasilchik (2000); Lopes (2000); Megid Neto e Pacheco (2001); Moreira (2000); Nardi (2014); Nardi e Almeida (2007); Schnetzler (2002); e Villani (1981, 1982).

A leitura desses trabalhos evidencia que a consolidação da área ocorreu a partir da ação de diferentes instituições, de problemas bastante variados e, como ocorre em outras áreas de humanas, com sustentação em referenciais teórico-metodológicos muitas vezes divergentes uns dos outros. Sendo assim, consideram-se que seria uma tarefa bastante complexa apontar os principais temas abordados nas pesquisas da Educação em Ciências.

Entretanto, dentre os muitos indícios da relevância de um tema em uma área de investigação, destaca-se, sem dúvida, sua inclusão nas linhas temáticas dos grandes eventos de pesquisa da área. Nesse sentido, com o intuito de abordar elementos da presença da Leitura na Educação em Ciências, busca-se a presença dessa abordagem nas atas dos três últimos Encontros de Pesquisa em Educação em Ciências (ENPEC), realizados em 2011, 2013 e 2015. Com pequenas variações no título das linhas: Linguagem e ensino de ciências no VIII ENPEC e Linguagens, discursos e educação em ciências no IX e X, nas ementas dessas três linhas, notase a presença da Leitura.

O estudo com leitura no âmbito do ensino de Ciências é anterior ao primeiro ENPEC, ocorrido em 1997. Esse fato fica evidente em um número especial do Journal of Reasearch in Science Teaching, de 1994 (volume 31, número 9). No início desse número, em uma nota, o ex-editor desse periódico afirmou que o aprendizado de ciências ocorre em grande medida pela leitura (GOOD, 1994). Também afirmou que compreender como estudantes interagem com a ciência retratada em textos é certamente uma área importante de pesquisa.

Artigos como Cook e Mayer (1988); Green e Meyer (1991); Guzzetti, Snyder e Glass (1992); Koch e Eckstein (1991); Ricon e Almeida (1991) são exemplos de trabalhos focados no estudo da leitura no ensino da ciência no final dos anos 1980 e início dos anos 1990, no Brasil e no exterior. 
Mais recentemente, trabalhos como Andrade e Martins (2006) e Suisso e Galieta (2015) são apenas dois exemplos de como a leitura na área de Educação em Ciências tem sido abordada com diferentes perspectivas. No primeiro deles, as autoras tomam os professores como mediadores das práticas escolares de leitura para problematizarem essas práticas, seus sentidos e representações sobre leitura, investigando os sentidos a ela atribuídos por um grupo de professores de ciências. Já no segundo, as autoras abordam, em periódicos nacionais da área, as distintas relações estabelecidas entre leitura/escrita e alfabetização científica ou letramento científico, localizando 21 artigos nessa perspectiva.

Uma evidência do envolvimento de pesquisadores da área de Educação em Ciências no Brasil com a leitura são as publicações resultantes de três encontros organizados pelo grupo de estudo e pesquisa em Ciência e Ensino (gepCE), realizados de 1995 a 1999 como parte dos Congressos de Leitura do Brasil desse período: o Caderno CEDES 41 - com o dossiê Ensino da Ciência Leitura e Literatura, organizado a partir do encontro Aspectos das Relações entre Ensino da Ciência, Leitura e Literatura, e publicado em 1997, bem como dois livros, organizados com capítulos de autores de comunicações no encontro de 1997 e no de 1999: Almeida e Silva (1998, 1999). Como pode ser notado nos títulos desses livros, a linguagem, a leitura e o ensino de Ciências são constituintes das questões centrais de seus capítulos, redigidos por pesquisadores oriundos de diferentes partes do país.

$\mathrm{Na}$ apresentação da primeira dessas produções, encontra-se a justificativa para a realização do encontro associada a como a ciência é apresentada na maioria das escolas. Ali os comentários remetem para o que ainda pode ser visto hoje em muitas escolas: uma prática estranha para grande parte dos sujeitos, a ciência como verdades absolutas, descontextualizadas e sem levar em conta o fato de ela ser fruto de um processo histórico de produção de saberes.

Esses comentários, indicadores da preocupação com o modo de ensinar ciência, encontram nos textos então publicados produções que indicam maneiras diferentes de fazê-lo, modos associados à temática do encontro. Já na apresentação do livro organizado a partir do III Encontro Linguagens, Leituras e Ensino da Ciência, realizado em julho de 1999, os autores falam no propósito de aprofundamento do estado da arte sobre o tema desse encontro da área de Educação em Ciências. Referem-se então ao propósito de, além de examinar estratégias de ensino, se debruçarem sobre representações associadas ao funcionamento das linguagens e a trazer outras linguagens, além da comum e matemática, para o centro da discussão da leitura, entre outros objetivos.

A constância da linguagem nos títulos anteriormente referidos remete para o fato de que não é possível falar em leitura sem falar em linguagem. E, nesse sentido, parte-se de uma citação: “[...] linguagem e significação não podem ser separadas, razão pela qual os conteúdos são próprios de cada linguagem [...]” (GULLAR, 2015, p. C8). Nessa coluna de jornal, o autor não se refere à ciência, mas à arte, apontando que cada tipo tem a sua própria linguagem. Entretanto, julga-se a pertinência dessa colocação no que se refere às linguagens em que as diferentes ciências são produzidas e ensinadas. Pense-se em apenas uma delas, a física: ela é essencialmente produzida em linguagem matemática e, se se acreditar na impossibilidade de separação entre significação e linguagem, nota-se a consequência que isso pode ter para a leitura de um texto de/sobre física - a impossibilidade de tradução total da linguagem matemática para a considerada comum. 
Nesse sentido, cabe aqui o comentário de Werner Heisenberg (1987, p. 127), quando aponta o uso da linguagem matemática pelo físico teórico na predição de resultados, mas também afirma que, “[...] ao expor seus resultados aos leigos em física, esses só se contentarão se a explicação oferecida for vazada em termos de linguagem comum [...]" e mais, "[...] mesmo para o físico, a capacidade de poder exibir uma exposição em linguagem simples constituir-se-á em um critério do grau de entendimento a que chegou [...]."

Como essa citação, evidencia, não se pode falar em apenas um tipo de linguagem. Assim, julga-se caber aqui a referência a algumas das concepções que podem ser subentendidas em diferentes manifestações de/sobre linguagem. Geraldi (1982) aponta três possibilidades de concebê-la: como expressão do pensamento; como instrumento de comunicação e como uma forma de ação. Sobre a primeira concepção, o autor diz que ela pode ter como consequência a crença de que quem não consegue se expressar linguisticamente não pensa; a segunda está associada à teoria da comunicação na qual a língua é vista como um código e, referindo-se à terceira, o autor (GERALDI, 1982, p. 53) afirma que “[...] mais do que possibilitar uma transmissão de informações de um emissor para um receptor, a linguagem é vista como um lugar de interação humana [...]".

Entretanto, essas três concepções não são as únicas possibilidades para se conceber a linguagem. Entre outras possíveis, refere-se aqui à concepção assumida pela análise de discurso de origem francesa na vertente pechetiana. Essa vertente, ao admitir que a linguagem não é transparente, considera-a em relação à constituição dos sujeitos e à produção dos sentidos, ressaltando o papel da exterioridade, “[...] já que sem história não há sentido, ou seja, é a inscrição da história na língua que faz com que ela signifique [...]" (ORLANDI, 1994, p. 53). Ou seja, a análise de discurso assume que os processos constituintes da linguagem são histórico-sociais.

No que se refere à leitura, Geraldi (1984) aponta quatro posturas que o leitor pode apresentar diante de um texto: buscar informações; estudar o texto; a leitura do texto-pretexto e a fruição do texto. Sem entrar aqui na caracterização de cada uma dessas posturas, julgase relevante apontar que, muitas vezes, o que ocorre não é propriamente a leitura, mas uma simulação: [...] assumem-se papéis de locutor/interlocutor durante o processo, mas não se é locutor/interlocutor efetivamente [...] (GERALDI, 1984, p. 25). Ao se referir à simulação, o autor comenta a artificialidade dessa situação.

Com relação à leitura, destacam-se aqui também alguns apontamentos da análise de discurso. Ao assumir que a linguagem não é transparente, admite-se que o sentido não é único, e isso não significa que ele possa ser qualquer um. Nesse sentido, segundo Orlandi (1988), quando se diz que os sentidos têm sua história, está-se enfatizando que a variação de sentidos "[...] tem relação com os funcionamentos distintos, ou seja, com os contextos de sua utilização [...]" (ORLANDI, 1988, p. 42) e, ao se afirmar que um texto tem relação com outros textos, a autora também enfatiza que "[...] não há leituras previstas por um texto, em geral, como se o texto fosse um objeto fechado em si mesmo [...]” (ORLANDI, 1988, p. 44).

Por outro lado, ao buscar evidenciar a relação estrita entre linguagem e leitura nos últimos parágrafos, e evidenciar diferentes posições a respeito de uma e de outra, a partir de autores da linguística, acredita-se ter contribuído para que se compreenda a existência na Educação em Ciências de estudos tão variados no que se refere às questões de investigação, aos objetivos e aos apoios teórico-metodológicos em relação à leitura. Esse fato fica evidente ao se 
notar nas atas do IX ENPEC a grande diferença estrutural entre dez trabalhos apresentados em comunicações orais e que tinham no título ou nas palavras-chave a palavra leitura, sendo que em todos o resumo remetia para a leitura de textos.

Esse fato, entretanto, parece bastante positivo, pois evidencia o amplo leque de possibilidades de investigação com abordagem da Leitura. Assim, um único limite se coloca a essa positividade, que é a possibilidade de, na realização dos estudos, as concepções pedagógicas dos autores e os demais aspectos estruturais do trabalho se mostrarem incoerentes entre si. Seria o caso, por exemplo, da utilização de uma concepção de leitura não compatível com a de linguagem.

Maria José P. M. de Almeida

Universidade Estadual de Campinas (Unicamp), Faculdade de Educação, Grupo de Estudo e Pesquisa em Ciência e Ensino (gepCE), Programa de Pós-Graduação Multiunidades em Ensino de Ciências e Matemática, Campinas, SP, Brasil.

E-mail: <mjpma@unicamp.br>

Cassiano Rezende Pagliarini

Universidade Estadual de Campinas (Unicamp), Faculdade de Educação, Programa de Pós-Graduação Multiunidades em Ensino de Ciências e Matemática, Campinas, SP, Brasil.

E-mail: <pagliarini@gmail.com> 


\section{Referências}

ALMEIDA, M. J. P. M. Meio século de educação em ciências: foco nas recomendações ao professor de física. São Paulo: LF Editorial, 2012.

O papel do professor no material para o ensino da física.

Ciência e Cultura, São Paulo, v. 41, n. 3, p. 264-268, 1989.

ALMEIDA, M. J. P. M.; SILVA, H. C. (Org.). Linguagens, leituras

e ensino de ciências. Campinas: Mercado de Letras, 1998.

Textos, palestras e sessões temáticas. In: ENCONTRO

LINGUAGENS, LEITURAS E ENSINO DA CIÊNCIA, 3., 1999, Campinas. Campinas: ALB-FE; UNICAMP, 1999.

ALMEIDA JR., J. B. A evolução do ensino de física no Brasil.

Revista de Ensino de Física, São Paulo, v. 1, n. 2, p. 45-58, 1979.

Disponível em: <http://www.sbfisica.org.br/rbef/pdf/vol01a17.

pdf>. Acesso em: 10 mar. 2016.

- A evolução do ensino de física no Brasil - 2a. parte.

Revista de Ensino de Física, São Paulo, v. 2, n. 1, p. 55-73, 1980.

ANDRADE, I. B.; MARTINS, I. Discursos de professores de ciências sobre leitura. Investigações em Ensino de Ciências, Porto Alegre, v. 11, n. 2, p. 121-151, 2006. Disponível em: <http:// www.if.ufrgs.br/ienci/artigos/Artigo_ID148/v11_n2_a2006.pdf>. Acesso em: 10 mar. 2016.

BARRA, V. M.; LORENZ, K. M. Produção de material didático no Brasil, período 1950 a 1980. Ciência e Cultura, São Paulo, v. 38, n. 12, p. 1970-1983, 1986.

COOK, L.; MAYER, R. E. Teaching readers about the structure of scientific text. Journal of Educational Psychology, Washington, v. 80, n. 4 , p. $448-456,1988$.

DELIZOICOV, D.; SLONGO, I. I.; LORENZETTI, L. Um panorama da pesquisa em educação em ciências desenvolvida no Brasil de 1997 a 2005. Revista Electrónica de Enseñanza de las Ciencias, Vigo, v. 12, n. 3, p. 459-480, 2013. Disponível em: <http://reec.uvigo.es/volumenes/volumen12/REEC_12_3_5_ ex718.pdf>. Acesso em: 10 mar. 2016.

FERREIRA, M. S.; GOMES, M. M.; LOPES, A. C. Trajetória da disciplina escolar ciências no Colégio de Aplicação da UFRJ (1949-1968). Pro-Posições, Campinas, v. 12, n. 1, p. 9-26, 2001. 
FERREIRA, M. S.; MOREIRA, A. F. B. A história da disciplina escolar ciências nas dissertações e teses brasileiras no período de 1981-1995. Ensaio: pesquisa em educação em ciências, Belo Horizonte, v. 3, n. 1, p. 117-132, 2001. Disponível em: < http://www. educadores.diaadia.pr.gov.br/arquivos/File/2010/artigos_teses/ Ciencias/Artigos/marciantonio.pdf>. Acesso em: 10 mar. 2016. GERALDI, J. W. Prática da leitura de textos na escola. Leitura: teoria e prática, Porto Alegre, v. 3, n. 3, p. 25-33, 1984.

Possíveis alternativas para o ensino da língua portuguesa.

Leitura: teoria e prática, Porto Alegre, v. 1, n. 4, p. 52-55, 1982.

GOOD, R. Note from former editor. Journal of Research in Science Teaching, Hoboken, v. 31, n. 9, p. 873, 1994.

GREEN, J. L.; MEYER, L. A. The embeddedness of reading in classroom life: reading as a situated process. In: BAKER, C.; LUKE, A. (Org.). Toward a critical sociology of reading pedagogy. Amsterdam: John Benjamins, 1991. p. 141-160.

GULLAR, F. Arte e personalidade. Folha de São Paulo, São Paulo, 15 nov. 2015. Folha Ilustrada, p. C8.

GUZZETTTI, B. J.; SNYDER, T. E.; GLASS, G. V. Promoting conceptual change in science: can texts be used effectively? Journal of Reading, Hoboken, v. 35, n. 8, p. 642-649, 1992.

HEISENBERG, W. Física e filosofia. Brasília: Editora Universidade de Brasília, 1987.

$\mathrm{KOCH}$, A.; ECKSTEIN, S. G. Improvement of reading comprehension of physics texts by students' question formulation. International Journal of Science Education, Abingdon, v. 13, n. 4, p. 473-486, 1991.

KRASILCHIK, M. Reformas e realidade: o caso do ensino de ciências. São Paulo em Perspectiva, São Paulo, v. 14, n. 1, p. 85-93, 2000.

LOPES, A. C. Currículo de ciências do Colégio de Aplicação da UFRJ (1969-1998): um estudo sócio histórico. Teias, Rio de Janeiro, v. 1, n. 2, p. 31-94, 2000.

MEGID NETO, J.; PACHECO, D. Pesquisas sobre o ensino de física no nível médio no Brasil: concepção e tratamento de problemas em teses e dissertações. In: NARDI, R. (Org.). Pesquisas em ensino de física. São Paulo: Escrituras, 2001. p. 15-30.

MOREIRA, M. A. Ensino de física no Brasil: retrospectiva e perspectivas. Revista Brasileira de Ensino de Física, São Paulo, v. 22, n. 1, p. 94-99, 2000. 
NARDI, R. Memórias do ensino de ciências no Brasil: a constituição da área segundo pesquisadores brasileiros, origens e avanços da pós-graduação. Revista do IMEA-UNILA, Foz do Iguaçu, v. 2, n. 2, p. 13-46, 2014.

NARDI, R.; ALMEIDA, M. J. P. M. Investigação em ensino de ciências no Brasil segundo pesquisadores da érea: alguns fatores que lhe deram origem. Pro-Posições, Campinas, v. 18, n. 1, p. 213-226, 2007.

ORLANDI, E. P. Discurso, imaginário social e conhecimento. Em Aberto, Brasília, v. 14, n. 61, p. 53-59, 1994.

Discurso e leitura. São Paulo: Cortez, 1988.

RICON, A. E.; ALMEIDA, M. J. P. M. Ensino da física e leitura. Leitura: teoria e prática, Porto Alegre, v. 10, n. 18, p. 7-16, 1991.

SCHNETZLER, R. P. A pesquisa em ensino de química no Brasil: conquistas e perspectivas. Química Nova, São Paulo, v. 25, supl. 1, p. 14-24, 2002.

SUISSO, C.; GALIETA, T. Relações entre leitura, escrita e alfabetização/letramento científico: um levantamento bibliográfico em periódicos nacionais da área de ensino de ciências. Ciência \& Educação, Bauru, v. 21, n. 4, p. 991-1009, 2015. Disponível em: <http://dx.doi.org/10.1590/1516-731320150040013>. Acesso em: 10 mar. 2016.

VILLANI, A. Considerações sobre a pesquisa em ensino de Física: a interdisciplinaridade. Revista de Ensino de Física, São Paulo, v. 3, n. 3, p. 68-88, 1981.

Considerações sobre a pesquisa em ensino de física - II: seus significados, seus problemas e suas perspectivas. Revista de Ensino de Física, São Paulo, v. 4, n. 1, p. 125-150, 1982.

Endereço para contato: Universidade Estadual de Campinas, Faculdade de Educação, Av. Bertrand Russell 801, Prédio Principal, Térreo, Bloco D, sala 06 (gepCE), Cidade Universitária, Barão Geraldo, CEP: 13083-865, Campinas, SP, Brasil. 